intenciones de un contrincante y en él adquiere más importancia los desplazamientos y el juego de pies. Es muy útil para comenzar a entrenar el ritmo de un combate, ya que no se ejecuta tan despacio como la forma en solitario. Aborda normas generales aplicables a cualquier combate y reglas propias del estilo que siempre deberían estar presentes en cualquier tipo de ejercicio de Tai Chi.

Por último, en el capítulo 5 expone unas reglas generales y métodos de estrategia de combate, aplicables tanto en una pelea real como ante peleas deportivas, haciendo reflexionar al lector sobre las consecuencias de escoger entre una técnica u otra, exponiendo sus ventajas y sus desventajas. La actitud mental ante el enfrentamiento, la distancia de combate, conocer al rival y conocerte a ti mismo, la manera de engañarlo y de entrar en contacto, etc., todo ello queda brevemente explicado por el autor en este capitulo.

Todos los capítulos del libro están construidos con gran cantidad de información muy bien explicada, acompañada de multitud de fotografías de calidad, pero que requieren de un largo proceso de asimilación, acompañado por la práctica y la experimentación con un compañero. El autor marca al alumno los pasos a seguir durante su proceso formativo dentro del Tai Chi Chuan, centrándose en el aspecto marcial. En primer lugar se aprende la forma en solitario, que nos enseña los principios de movimiento y las reglas básicas, así como la teoría del sistema. Cuando todo ello se domina, se comenzaría con lo que el autor expone en este libro: conocer las aplicaciones, practicar el empuje de manos, la secuencia de pareja y por último, la práctica libre. En resumen, me parece un libro muy interesante y muy recomendable para todos aquellos practicantes que deseen indagar en el origen y los principios básicos del Tai Chi Chuan, y también para aquellos que busquen conocer la vertiente más marcial del estilo Yang y que tengan unas nociones de Tai Chi y que suelan practicar de forma habitual.

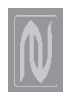

\section{The empty mind. The Spirit and Philosophy of Martial Arts}

Por Budo Films \& Thinmedia

Miami Beach: ThinMedia Inc., 2004

DVD $\bullet 78$ min. $\bullet 34,44 €$

Idioma: Inglés

Disponible en:

Kamikaze Esp.

Telf.: +34962740663.

Fax: +34962740876.

E-mail: info@kamikazeweb.com

Http://www.kamikazeweb.com

ThinMedia Inc.

301 41st Street 3rd Floor

Miami Beach. FL 33140 (USA)

Telf.: +01 305.604.7989

Http://budofilms.com/

Http://theemptymind.com/

\section{Revisión por Carlos Gutiérrez García}

"Os recordaremos una historia popular...

El estudiante se sienta delante de su maestro de zen, haciéndole muchas preguntas, mientras el maestro de zen vierte té. Mientras continúa la charla, la taza se llena, pero el maestro zen sirve té hasta que el té se derrama por todas partes. 'Tu mente es como la taza', dice al alarmado estudiante. 'Está llena, ¿cómo puedes aprender cualquier cosa? Primero tienes que aprender a vaciar la mente"."

"Se llama Mushin. De Mu -'nada'y Shin -"mente". Sin mente. Verdadero vacio".

Con estas frases comienza el DVD The empty mind. The Spirit and Philosophy of Martial Arts [La mente vacía. El espíritu y filosofía de las artes marciales], un documental de 78 minutos de duración que trata de aproximar al espectador a un concepto holístico de las artes marciales como medios de desarrollo del ser humano. Podríamos calificar ésta como la visión más "espiritual”, e incluso más "romántica" -vista la orientación principal que han tomado algunas disciplinas- de las artes marciales, siendo una filosofía que siempre las ha acompañado y que este documental explota brillantemente.

Comenzando por el kung fu de los monjes del Templo Shaolín, el lugar donde según el narrador, "todo empezó, hace 500 años" (aunque esta afir- mación esté cada vez más discutida), el director Jon Braeley nos embarca en un hermoso viaje a lo largo de diferentes escuelas y estilos marciales tratando de buscar un nexo común. En este viaje no se han escatimado esfuerzos. Para la realización del documental se ha viajado a muchos de los emplazamientos míticos de las artes marciales como son el propio Templo Shaolin, el Templo de la Nube Morada de la montaña Wudang, el Aikiai Hombu Dojo, el Budokan de Tokio o los dojos de la Asociación Japonesa de Kárate y de la Federación Internacional de Shotokan Karate-Do. También se ha contado con algunos de los más reputados maestros de cada estilo. Siendo la lista notablemente larga -aquellos lectores interesados pueden remitirse a la página web del producto Http://theemptymind.com- me limitaré a citar como ejemplo a Moriteru Ueshiba, nieto del fundador del aikido Morihei Ueshiba y actual Doshu ("Cabeza del Camino") de dicho arte. Personalmente echo de menos que no se haga ninguna referencia al judo, no sólo porque sea mi arte marcial sino porque es una de las artes marciales más extendidas y que también posee un importante sustrato ético y filosófico.

Los conceptos que se desarrollan en el documental seguramente serán conocidos para cualquier artista marcial preocupado de su arte. A modo de gotas de agua, la narración va sugiriendo aspectos como el vacío de la mente, la importancia del entrenamiento continuo, la actitud de entrega total, el arte marcial como camino, la unión de lo físico, lo mental y lo espiritual, la actitud de superación de uno mismo, etc., que si bien, como señalamos, nos resultan familiares, no por ello está mal recordarlos, a veces por boca de grandes maestros.

Los esfuerzos por contar con estos grandes maestros de las artes marciales van a la par con los realizados para que el producto final sea visualmente atractivo para el espectador, cumpliendo todos los requisitos que pueden exigirse a un buen DVD (carátulas de calidad, menú, facilidad de navegación, algunos contenidos extra, etc.). Para alivio de posibles interesados, señalaré que el inglés del narrador es perfectamente comprensible para cualquier persona que tenga un nivel medio en el idioma. 
Pero esto no es todo, y desde luego no es lo más importante. Lo que personalmente me parece más destacable es la calidad estética del documental en sí. Las imágenes, secuencias, ritmos, sonidos -además de la voz del narrador y de algunos de los maestros, el documental tiene una preciosa banda sonora de música de instrumentos tradicionales- son de una calidad extraordinaria, resultado de un proceso de producción muy profesional. Sólo por este motivo, por ver algunos de los emplazamientos más bellos donde se desarrollan las artes marciales, y por ver las actuaciones de los monjes Shaolín, de los maestros de tai-chi, wu-shu, kyudo, kendo, kárate o aikido, merece la pena sentarse a ver este DVD.

En definitiva, The empty mind. The Spirit and Philosophy of Martial Arts es un producto para el consumo masivo, pero un producto de consumo masivo de una gran calidad. Cualquiera de las cadenas de televisión actuales -obviamente aquellas preocupadas por dotar de un cierto nivel cultural a sus contenidos- no tendría problema en emitir este documental, pudiendo tener como espectadores, al mismo tiempo, a personas que apenas saben nada de las artes marciales, a principiantes y a profesores o maestros. Y, posiblemente, todos disfrutarían de este hermoso documental.

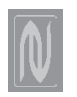

\section{Mind Over Muscle: Writings From the Founder of Judo}

Por Jigoro Kano

Tokyo: Kodansha Internacional, 2006

160 páginas. $12,7 \times 19 \mathrm{~cm}$.

I.S.B.N.: 47-7003-015-0 • \$19.95

Idioma: Inglés

Disponible en:

Kodansha International Inc. c/o Oxford University Press

2001 Evans Road

Cary, NC 27513

Telf: + 1800.451 .7556

Fax: +1 991.677.1303

www.thejapanpage.com

\section{Revisión por Damon Young}

Para muchas personas, las palabras “artes marciales japonesas” evocan imá- genes de monjes voladores, chorros de sangre y dientes rotos, o gamberros musculosos con puños callosos. Aunque sean muy populares en Occidente, las artes marciales japonesas evocan frecuentemente miedo, mistificación o simplemente un grito "¡whoohaaaah!” a lo Bruce Lee. Ciertamente, las artes marciales han atraído un gran número de artistas, gamberros y comediantes decididos a obtener un rápido reconocimiento o remuneración.

Sin embargo no todas las artes marciales tratan de esto. La reciente publicación de los escritos del Dr. Jigoro Kano, Mind Over Muscle: Writings From the Founder of Judo, es un ejemplo de estas ideas. En este libro bellamente encuadernado, de pastas duras, publicado por Kodansha, se desarrollan las ideas del fundador del judo en tres sencillos capítulos: "El desarrollo del judo", "El espíritu del judo", y "Entrenamiento del judo". Aunque no esté ilustrado, como el Kodokan Judo del mismo Kano, este breve libro ofrece una visión mucho mejor de su visión del judo. Como su contemporáneo Funakoshi Gichin, el fundador del kárate moderno, Kano veía el judo como mucho más que un modo de magullar, romper y estrangular a un enemigo. En vez de ello, concebía el judo como un modo de desarrollo físico, intelectual y moral. Mientras que muchas escuelas de artes marciales hablan de estas cosas, lo que define a esta colección de escritos es la claridad y simplicidad con la que están orientados, con cada capítulo estructurado en sucintas subsecciones y repleto de anécdotas clarificantes. Por supuesto esto no es una coincidencia, tal y como señala el epílogo de Murata Naoki, ya que Kano era el director de la primera Escuela Normal de profesores de Japón. En otras palabras, era un educador. Esto significa no sólo que sus escritos son educativos en eficacia y efectividad, sino que también el judo mismo fue desarrollado como un método educativo para viejos y jóvenes, hombres y mujeres, japoneses y no japoneses. Ciertamente, una de las razones por las que los escritos de Kano siguen siendo importantes para las audiencias contemporáneas es que fueron elaborados para combatir vicios como la pereza y el egoísmo, las pesadillas de las genera- ciones criadas en las políticas neoliberales, videojuegos y la televisión de los "reality".

Por tanto, ¿cómo llega el judo a los "emprendedores" de este camino de "desinterés"? En Mind Over Muscle el principio esencial de Kano es traducido por Nancy H. Ross como "el mejor uso de la energía”. Por ejemplo, durante la práctica del judo los estudiantes se enfrentan a menudo con oponentes más grandes y fuertes. En vez de enfrentar fuerza contra fuerza, el mejor uso de su energía es usar la fuerza de su oponente contra él, de tal modo que este se vea en un compromiso, sea desequilibrado, etc. Cuando se golpea o se rompe una inmovilización la fuerza puede ser un valor. La idea no es usar la fuerza todo el tiempo o la suavidad todo el tiempo, sino hacer el mejor uso de lo que tengamos: el mejor uso de la propia energía, o simplemente "máxima eficiencia". Este principio de "máxima eficiencia" puede ser aplicado a la vida cotidiana, que significa no gastar energía en quejarse o encolerizarse. Significa no desperdiciar tiempo y energía en sentirse frustrado, enfadado o dolido. Si tenemos metas claras hemos de usar la energía para lograrlas paciente pero decisivamente, sin malgastarlas en diversiones inútiles o gratificaciones a corto plazo. En conclusión, significa fijar la mirada en nuestro destino y en el camino que nos llevará allí.

Para Kano es en este "caminar el camino" para lo que el judo es especialmente útil. Para aquellos que nunca hayan visto judo esta práctica involucra fundamentalmente a hombres adultos proyectándose uno al otro, luchando y generalmente sudando todo el tiempo en una danza mano a mano habitualmente elegante -aunque a veces no-. En el combate, argumenta Kano, los estudiantes desarrollan algunas habilidades esenciales: observación, memoria, experimentación, imaginación, lenguaje y amplitud de mente. La observación es necesaria para aprender, y la memoria es importante para retener lo que se aprende. Le experimentación es esencial para aprender nuevas técnicas en situaciones variadas, y la imaginación ayuda a los estudiantes a desarrollar nuevas técnicas o a visualizarlas en situaciones 